\title{
A Transient Thermal Model for Flat-Plate Photovoltaic Systems and Its Experimental Validation
}

\author{
Bojan Perovic $^{1}$, Dardan Klimenta ${ }^{1}$, Miroljub Jevtic ${ }^{1}$, Milos Milovanovic ${ }^{1}$ \\ ${ }^{1}$ Faculty of Technical Sciences Kosovska Mitrovica, University of Pristina in Kosovska Mitrovica, \\ Kneza Milosa St. 7, RS-38220 Kosovska Mitrovica, Serbia \\ bojan.perovic@pr.ac.rs
}

\begin{abstract}
This paper describes a transient thermal model that accurately predicts the temperature of the open-rack mounted photovoltaic (PV) modules under varying atmospheric conditions. The PV module temperature is predicted by considering the thermal energy exchange between the PV module and its environment through the main heat transfer paths. The proposed thermal model has been validated by utilising data from the experiment: the temperature measurement of two identical PV modules operating in two different modes (open-circuit and full-load) was performed by means of three temperature sensors placed on the back surface of both PV modules. The model accuracy is $3^{\circ} \mathrm{C}$ of measured temperature values $100 \%$ of the time under all conditions. The highest accuracy is obtained when the solar irradiance is subject to less fluctuation. The influence of the load level relative to the nominal power of the PV module on its temperature is hereby subject to consideration.
\end{abstract}

Index Terms-Photovoltaic systems; Temperature; Transient thermal model.

\section{INTRODUCTION}

The accurate value of the PV module temperature is of crucial importance for the precise estimation of its performance [1]-[3]. Consequently, there are a lot of papers in the literature concerning the modelling of the PV module temperature. Most of these models are valid under the steady-state operating conditions [2], [4]-[6], while a number of them consider the transient change in ambient conditions [7]-[10]. The steady-state models are simple to implement, yet are generally only applicable to the hourlyaveraged data, such as solar irradiance, wind velocity and ambient temperature or cases when these parameters do not change over a long time interval.

King et al. have proposed one such steady-state model concerning a flat-plate module in an open-rack mounting configuration [11]

$$
T_{P V}=G \times \exp \left(-3.56-0.075 v_{w}\right)+T_{a} .
$$

This model, also known as the SNL (Sandia National Laboratories) model, uses ambient temperature $T_{a}$, global

Manuscript received 3 October, 2018; accepted 6 January, 2019.

This research was funded by a grant (No. TR33046) from the Government of the Republic of Serbia. solar irradiance $G$, and wind velocity $v_{w}$ as inputs to calculate PV module temperature $T_{P V}$.

If a precise prediction of the PV module temperature is required in case when meteorological parameters change rapidly, which is a much more frequent and realistic situation in practice (especially under the cloudy sky conditions), then the transient models should be used. In these models, unlike steady-state ones, the PV module temperature changes gradually with the change of any parameter affecting it. This thermal inertia occurs due to the existence of the thermal masses of the PV module materials that are taken into account through the heat capacity of these materials. There are a few transient thermal models for predicting the PV module temperature in the literature. All of these models are based on the principle of energy balance between incoming heat and heat losses due to electrical conversion, radiation, and convection heat transfer. Fuentes has proposed one of the first transient thermal models for predicting the PV module temperature [7]. Determination of the INOCT ("Installed" Nominal Operating Cell Temperature) is essential for the application of this model. INOCT is the cell temperature of an installed array under NOCT conditions and depends on the PV module type (mono-crystalline, poly-crystalline, amorphous, etc.), mounting configuration (open-rack or close-roof mount), and also on the PV module manufacturer. Accordingly, it is very difficult to estimate this temperature precisely. Jones and Underwood have proposed a transient thermal model for predicting the PV module temperature [8]. This model does not require knowledge of the INOCT. However, this model does not include the influence of the wind velocity on the forced convection coefficient or the influence of the PV module inclination angle on the free convection coefficient. Luketa-Hanlin and Stein made improvements to this model by introducing a linear dependence between the forced convection coefficient and the wind velocity [10]. The transient thermal model proposed in this paper does not require any knowledge of INOCT and considers the powerlaw correlations for calculating the forced convection coefficients instead of linear ones. In addition, the model includes the influence of the load level relative to the nominal power of the PV module on its temperature. Due to the fact that the radiation coefficients for the front and back 
PV module surface to the surroundings produce different PV module temperatures, this temperature is determined iteratively. The proposed thermal model has been validated under dynamic conditions. Several comparisons were made between the model and actual field data collected by the measurements, where a good agreement between the temperatures obtained by the model and experiments was confirmed for all operating modes of the PV modules and all atmospheric conditions.

\section{MODEL DESCRIPTION}

A part of the global solar irradiance $G$ incident on the PV module front surface is converted into electric power $P_{e l}$ depending on the instantaneous efficiency $\eta_{P V}$ of the PV module. The remaining energy is converted into heat. It is considered that the heat exchange between a PV module and its environment is realised by means of three heat transfer modes - conduction, convection and radiation. The most significant modes are convection and radiation, whilst heat conducted from the PV module to the structural framework is considered negligible due to the small area of contact points. A PV module can be modelled as a single lump of solid material at a uniform temperature $T_{P V}$ (Fig. 1).

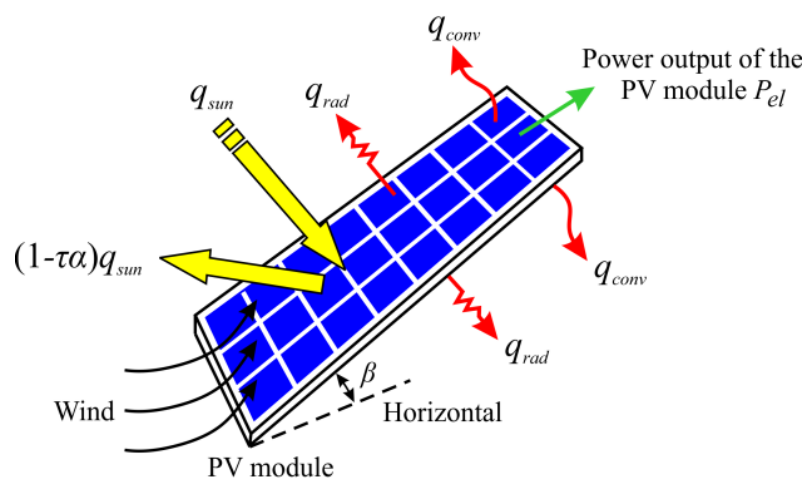

Fig. 1. Schematic depiction of heat exchanges between a PV module and surroundings.

The transient heat balance equation of the system from Fig. 1 is as follows

$$
C_{P V} \mathrm{~d} T_{P V} / \mathrm{d} t-q_{\text {sun }}+q_{c o n v}+q_{r a d}+P_{e l}=0
$$

where $C_{P V}$ is the heat capacity of a PV module in $\mathrm{J} / \mathrm{K}, q_{\text {sun }}$ is the net rate of solar irradiance in $\mathrm{W}, q_{\text {conv }}$ is the net rate of heat transfer due to convection in W, $q_{\text {rad }}$ is the net rate of heat transfer due to radiation in $\mathrm{W}$ and $P_{e l}$ is the power output in $\mathrm{W}$.

The heat capacity $C_{P V}$ is required in the model to simulate the thermal lag of a PV module. According to [7], the exact value of $C_{P V}$ is not required, because $50 \%$ variations in the value of $C_{P V}$ will not appreciably change the results of the model. Luketa-Hanlin and Stein have established the fact that the optimal value of the $C_{P V}$ parameter, for which the best agreement between simulated and experimentally determined temperatures is achieved, for the typical PV module amounts to $C_{P V}=22800 \mathrm{~J} / \mathrm{K}$ [10]. This value is also used in this paper. The proposed model incorporates the influence of the PV module temperature on its power output, which was not considered in similar models [7], [8], [10].
The components of (2) are broken down as follows:

$$
\begin{gathered}
q_{\text {sun }}=A G(\tau \alpha), \\
q_{\text {rad }}=A\left(h_{\text {rad }, f}\left(T_{P V}-T_{s k y}\right)+h_{\text {rad }, b}\left(T_{P V}-T_{\text {ground }}\right)\right), \\
h_{\text {rad }, f}=\sigma_{S B}\left(T_{P V}^{2}+T_{s k y}^{2}\right)\left(T_{P V}+T_{\text {sky }}\right) \varepsilon_{f} \times \\
\times(1+\cos (\beta)) / 2+\sigma_{S B}\left(T_{P V}^{2}+T_{\text {ground }}^{2}\right) \times \\
\times\left(T_{P V}+T_{\text {ground }}\right) \varepsilon_{f}(1-\cos (\beta)) / 2, \\
h_{\text {rad }, b}=\sigma_{S B}\left(T_{P V}^{2}+T_{s k y}^{2}\right)\left(T_{P V}+T_{\text {sky }}\right) \varepsilon_{b} \times \\
\times(1+\cos (\pi-\beta)) / 2+\sigma_{S B}\left(T_{P V}^{2}+T_{\text {ground }}^{2}\right) \times \\
\times\left(T_{P V}+T_{\text {ground }}\right) \varepsilon_{b}(1-\cos (\pi-\beta)) / 2, \\
q_{\text {conv }}=A\left(h_{f}+h_{b}\right)\left(T_{P V}-T_{A}\right), \\
h_{f}=\sqrt[3]{h_{f, \text { free }}^{3}+h_{f, \text { forced }}^{3}}, \\
h_{b}=\sqrt[3]{h_{b, \text { free }}^{3}+h_{b, \text { forced }}^{3}} .
\end{gathered}
$$

Correlations for the free convection coefficients for the front and back surface of the PV module inclined at an angle $\theta$ from the vertical are shown in (10) and (11), respectively [4]. The correlations are valid for angle $\theta$ less than $60^{\circ}$ :

$$
\begin{aligned}
& h_{f, \text { free }}=\left(\begin{array}{l}
0.13\left((G r \operatorname{Pr})^{1 / 3}\right)-\left(G r_{c} \operatorname{Pr}\right)^{1 / 3}+ \\
+0.56\left(G r_{c} \operatorname{Pr} \times \cos (\theta)\right)^{1 / 4}
\end{array}\right) k / L, \\
& h_{b, \text { free }}=\left(\frac{0.825+0.387(\operatorname{Ra} \times \cos (\theta))^{1 / 6}}{\left(1+(0.492 / \operatorname{Pr})^{9 / 16}\right)^{8 / 27}}\right)^{2} k / L,
\end{aligned}
$$

where:

$$
\begin{gathered}
G r_{c}=1.327 \times 10^{10} \exp \left(-3.708 \theta_{r}\right), \\
R a=g\left(1 / T_{f}\right)\left(T_{P V}-T_{a}\right) L^{3} /(v \alpha), \\
G r=R a / \operatorname{Pr} .
\end{gathered}
$$

Equation (10) is valid for $R a>5 \times 10^{8}$, and (11) is valid for $10^{5}<R a \times \cos (\theta)<10^{11}$ which holds for all data in the present study. In case of lower $R a$ values and $\theta \geq 60^{\circ}$, a similar set of equations is provided by Fujii and Imura [12].

In (3)-(14), the variables have the following meaning: $A$ is the area of the PV module in $\mathrm{m}^{2}, \tau \alpha$ is the transmissionabsorption coefficient for the front PV module surface (equal to 0.855 according to [3]), $h_{\text {rad,f }}$ and $h_{\text {rad,b }}$ are the radiation coefficients for the front and back PV module surface to the surroundings, respectively, in $\mathrm{W} /\left(\mathrm{m}^{2} \mathrm{~K}\right), T_{s k y}$ and $T_{\text {ground }}$ are the sky and the ground temperatures, respectively in $\mathrm{K}, \varepsilon_{f}$ and $\varepsilon_{b}$ are the emissivity coefficients for the front and back PV module surface, respectively, $\beta$ is the $\mathrm{PV}$ module inclination angle with respect to the horizontal in degrees, $\sigma_{S B}$ is the Stefan-Boltzmann constant equal to $5.67 \times 10^{-8} \mathrm{~W} /\left(\mathrm{m}^{2} \mathrm{~K}^{4}\right), h_{f}$ and $h_{b}$ are the overall convection coefficients for the front and back PV module surface, respectively, in $\mathrm{W} /\left(\mathrm{m}^{2} \mathrm{~K}\right), h_{f, \text { free }}$ and $h_{\text {fforced }}$ are the free and forced convection coefficients for the front PV module 
surface, respectively, in $\mathrm{W} /\left(\mathrm{m}^{2} \mathrm{~K}\right), h_{b, \text { free }}$ and $h_{b, \text { forced }}$ are the free and forced convection coefficients for the back PV module surface, respectively, in $\mathrm{W} /\left(\mathrm{m}^{2} \mathrm{~K}\right), \mathrm{Gr}$ is the Grashof number, $G r_{c}$ is the critical Grashof number (the value at which the Nusselt number starts deviating from laminar behaviour), $\operatorname{Pr}$ is the Prandtl number, $k$ is the thermal conductivity of air in $\mathrm{W} /(\mathrm{mK}), L$ is the length of the PV module along the natural air flow direction in $\mathrm{m}, R a$ is the Rayleigh number, $\theta_{r}$ is the inclination angle of the PV module with respect to the vertical in radians, $g$ is the gravitational constant equal to $9.81 \mathrm{~m} / \mathrm{s}^{2}, T_{f}$ is the film temperature of the air boundary layer around the PV module in $\mathrm{K}, v$ is the kinematic viscosity of the air in $\mathrm{m}^{2} / \mathrm{s}$, and $\alpha$ is the thermal diffusivity of the air in $\mathrm{m}^{2} / \mathrm{s}$.

Based on the empirical data, Adkins has reported that the power-law correlations for calculating the forced convection coefficients are the most appropriate for the PV modules [13]. Balog et al. have proposed one such correlation for the front and back surface of the PV module [14]

$$
h_{f, \text { forced }}=h_{b, \text { forced }}=0.931 \rho c_{p}\left(v_{w} v / L_{c}\right)^{0.5} / \operatorname{Pr}^{2 / 3} \text {, }
$$

with the characteristic length of

$$
L_{c}=A /\left(2\left(L_{P V}+W_{P V}\right)\right) .
$$

The kinematic viscosity $v$ in $\mathrm{m}^{2} / \mathrm{s}$, conductivity $k$ in $\mathrm{W} /(\mathrm{mK})$, density $\rho$ in $\mathrm{kg} / \mathrm{m}^{3}$, specific heat $c_{p}$ in $\mathrm{J} /(\mathrm{kgK})$ and Prandtl number Pr are the properties of the air at temperature $T_{f}$ and all of them are determined using curve-fitting software.

An often used formula for the prediction of the sky temperature is given by Swinbank and is used in this study [15]

$$
T_{s k y}=0.0552 T_{a}^{1.5}
$$

The ground temperature has been taken in various PV module studies as equal to the ambient temperature [16]

$$
T_{\text {ground }}=T_{a} \text {. }
$$

As mentioned earlier, the proposed thermal model takes into consideration the influence of the load level relative to the nominal power of the PV module on its temperature through the load coefficient of the PV module $x$. This coefficient defines the PV module load mode ( $x=0$ - opencircuit mode, $x=1$ - full-load mode) and may assume any value between these limits

$$
P_{e l}=x \eta_{T_{r e f}} A G(\tau \alpha)\left(1-\beta_{r e f}\left(T_{P V}-T_{r e f}\right)\right) .
$$

The variables, which have not been defined earlier, have the following meaning: $v_{w}$ is the wind velocity in $\mathrm{m} / \mathrm{s}, L_{P V}$ is the height and $W_{P V}$ the width of the PV module in $\mathrm{m}, \eta_{\text {Tref }}$ is the electrical efficiency of the PV module at the reference temperature $T_{r e f}$ and the global solar irradiance of 1000 $\mathrm{W} / \mathrm{m}^{2}, \beta_{\text {ref }}$ is the temperature coefficient of the PV module in $1 / \mathrm{K}$, and $T_{\text {ref }}$ is the temperature at which the PV module's electrical efficiency amounts to $\eta_{\text {Tref }}$ in K.

The PV module temperature is obtained as the solution of a differential equation (2) using the Euler method and can be described by following equation

$$
T_{P V}(t+1)=T_{P V}(t)+s t e p \times \mathrm{d} T_{P V} / \mathrm{d} t,
$$

where

$$
\mathrm{d} T_{P V} / \mathrm{d} t=\left(\begin{array}{l}
\left(h_{f}+h_{b}\right) T_{a}+h_{r a d, f} T_{s k y}+ \\
+h_{r a d, b} T_{g}+G(\tau \alpha) \times \\
\times\left(1-x \eta_{T_{r e f}}\left(1+\beta_{r e f} T_{r e f}\right)\right)- \\
-\left(\begin{array}{l}
h_{f}+h_{b}+h_{r a d, f}+ \\
+h_{r a d, b}- \\
-x G(\tau \alpha) \eta_{T_{r e f}} \beta_{r e f}
\end{array}\right)
\end{array}\right) A / C_{P V} .
$$

In equation (20), $t$ is the time in s, and step is the time step between each data point in $s$. The Euler method requires an initial value of PV module temperature. The measured starting value of $T_{P V}$ will be used as the initial value in this paper. In predicting the PV module temperature using the proposed model, the initial value of this temperature is not known and it can be estimated using a steady-state model. In this case, an error may occur because the steady-state models do not take into consideration the heat capacity of the PV modules. According to [8], to avoid the error in the initial temperature, a preconditioning period of simulation for 30 time steps is recommended.

Equations (5) and (6) represent the Stefan-Boltzmann law. Linearisation of these two equations is carried out here according to the procedure described in [7].

After solving for $T_{P V}$, the values of $h_{r a d, f}$ and $h_{r a d, b}$ in equations (5) and (6) may be reestimated, respectively, and then may be solved for $T_{P V}$ again. A nearly exact solution may be obtained after 5-6 iterations. Such iterative procedure is carried out for each step of the Euler method as shown in the flowchart in Fig. 2. The parameters from the flowchart, which have not been explained earlier, have the following meanings: $\boldsymbol{T}_{\boldsymbol{a}}, \boldsymbol{v}_{\boldsymbol{w}}$ and $\boldsymbol{G}$ are the vectors with the ambient temperature values, wind velocity and solar irradiance, respectively, $h$ is the initial value of the convection coefficient arbitrarily assigned by the user (the program makes a minimal number of iterations, if this value is selected from the 5-15 range), $j$ is the control variable, $T_{P V 1}$ and $T_{P V}$ are the program variables reserved for the PV module temperature.

\section{DESCRIPTION OF EXPERIMENTAL SETUP}

The measurements of the PV module temperature, solar irradiance, wind velocity and ambient temperature were carried out in a village of Prelez (the municipality of Zubin Potok, Serbia). The experimental setup was composed by two BISOL BMO255 mono-crystalline PV modules, each with a nominal power output of $255 \mathrm{~W}$, KIMO SL100 portable solarimeter, TFA sinus weather station for measuring the ambient temperature and wind velocity, and Agilent 34970a data acquisition/switch unit with six 
temperature sensors of the $\mathrm{J}$ type for measurement of the PV module temperature. The data acquisition was repeated every 33 seconds. The temperature sensors were attached directly on the back side of the PV modules at three points (top, middle and bottom) using the adhesive tape.

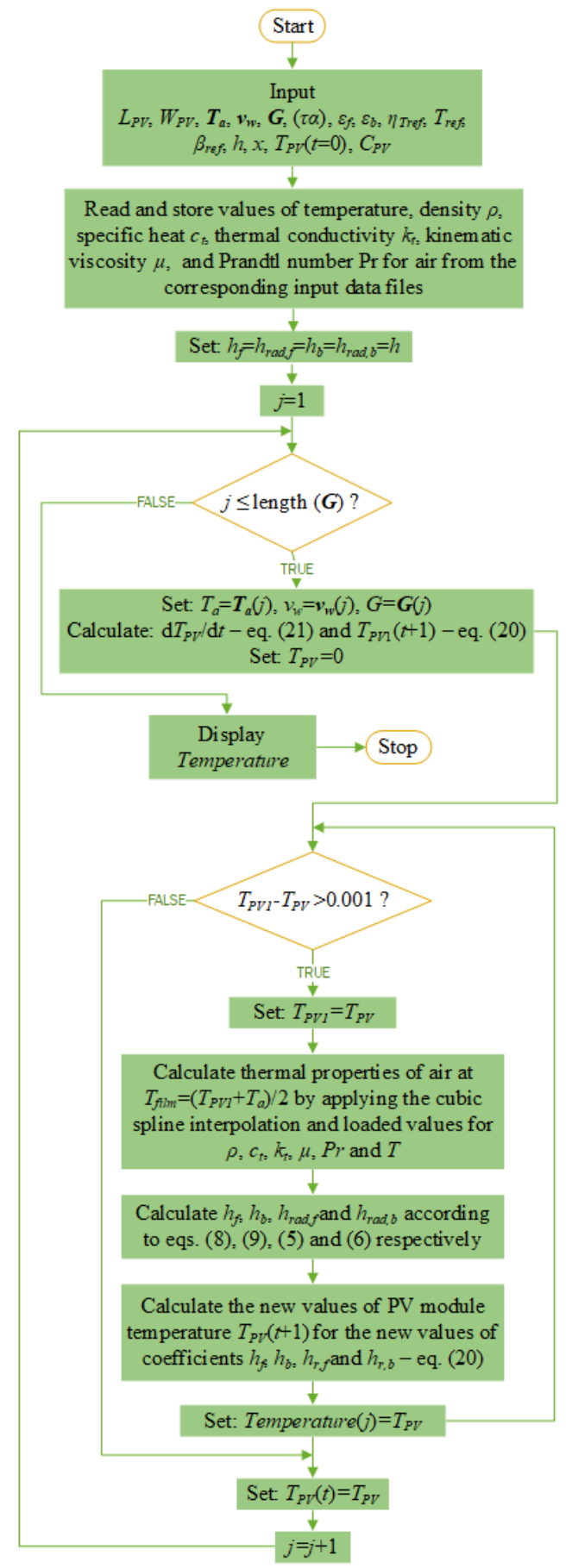

Fig. 2. Flowchart of the proposed thermal model.

The PV module temperature was then calculated based on the average of measured temperatures on the module back side. The operating ranges of all measurement systems are given in Table I. A schematic depiction of the experimental setup is presented in Fig. 3, and a photograph of the assembled experimental setup during measurement is shown in Fig. 4. The PV modules were south oriented and fixed at an angle of $43^{\circ}$, respectively, which is the latitude of the village of Prelez. Both examined PV modules were tested under the same conditions, except that one PV module operated in the full-load mode (400 W halogen lamp) and the other one in the open-circuit mode. This is for the purpose of observing the influence of the power output of the PV module on its temperature, which is taken into consideration by the proposed thermal model. Temperature measurements were performed on two different days, namely $11 / 07 / 18$ and $25 / 07 / 18$. These days were chosen for their different wind speed and solar irradiance values.

All the technical information about the PV modules used in this study, as well as the optical characteristics of the front and back surface of the PV module, are given in Table II.

TABLE I. OPERATING RANGE AND ACCURACY OF THE EXPERIMENTAL MEASUREMENT EQUIPMENT USED IN THE PRESENT STUDY.

\begin{tabular}{|c|c|c|}
\hline \multicolumn{2}{|c|}{ Device name } & Operating range \\
\hline \multicolumn{2}{|c|}{$\begin{array}{l}\text { Agilent 34970a data logger (for J- } \\
\text { type thermocouple) }\end{array}$} & $-150{ }^{\circ} \mathrm{C}$ to $1200^{\circ} \mathrm{C}$ \\
\hline \multicolumn{2}{|c|}{$\begin{array}{c}\text { Temperature sensors (J-type } \\
\text { thermocouples) }\end{array}$} & $-210^{\circ} \mathrm{C}$ to $760{ }^{\circ} \mathrm{C}$ \\
\hline \multicolumn{2}{|c|}{ KIMO SL100 solarimeter } & $\begin{array}{c}1 \mathrm{~W} / \mathrm{m}^{2} \text { to } 1300 \mathrm{~W} / \mathrm{m}^{2}, \\
-10{ }^{\circ} \mathrm{C} \text { to }+50{ }^{\circ} \mathrm{C}\end{array}$ \\
\hline \multirow{2}{*}{$\begin{array}{c}\text { TFA sinus } \\
\text { weather station }\end{array}$} & $\begin{array}{c}\text { Ambient } \\
\text { temperature }\end{array}$ & $-40^{\circ} \mathrm{C}$ to $+80^{\circ} \mathrm{C}$ \\
\hline & Wind speed & $0 \mathrm{~m} / \mathrm{s}$ to $90 \mathrm{~m} / \mathrm{s}$ \\
\hline
\end{tabular}

TABLE II. TECHNICAL AND OPTICAL CHARACTERISTICS OF THE PV MODULES USED IN THE PRESENT STUDY.

\begin{tabular}{|c|c|}
\hline Characteristics of PV module $^{*}$ & BISOL BMO255 \\
\hline Length & $1.649 \mathrm{~m}$ \\
\hline Width & $0.991 \mathrm{~m}$ \\
\hline Nominal power & $255 \mathrm{~W}$ \\
\hline Maximal power voltage/open-circuit voltage & $30.7 \mathrm{~V} / 38.1 \mathrm{~V}$ \\
\hline $\begin{array}{c}\text { Maximal power circuit current/short-circuit } \\
\text { current }\end{array}$ & $8.30 \mathrm{~A} / 8.90 \mathrm{~A}$ \\
\hline Solar cell efficiency & $17.5 \%$ \\
\hline Power temperature coefficient & $-0.4 \% /{ }^{\circ} \mathrm{C}$ \\
\hline $\begin{array}{c}\text { Emissivity coefficients for the front PV module } \\
\text { surface (glass cover) }\end{array}$ & 0.91 \\
\hline $\begin{array}{c}\text { Emissivity coefficients for the back PV module } \\
\text { surface }\end{array}$ & 0.9 \\
\hline
\end{tabular}

${ }^{*}$ Note: PV module characteristics at solar irradiance of $G=1000 \mathrm{~W} / \mathrm{m}^{2}$ and $T_{a}=25{ }^{\circ} \mathrm{C}$.

\section{RESUlTS AND DISCUSSION}

Figure 5 shows the variations of the three meteorological parameters, namely ambient temperature, solar irradiance and wind velocity during the two days. On 25/07/18 the solar irradiance variations were rapid and great and wind velocity was higher than $2.5 \mathrm{~m} / \mathrm{s}$, while on 11/07/18 the solar irradiance variations were significantly less and wind velocity was less than $1.6 \mathrm{~m} / \mathrm{s}$. Figures 6 and 7 show the measured and simulated PV module temperatures for the two above mentioned days.

From the Fig. 6 it is evident that the change in the PV module temperature calculated using the proposed thermal model is very gradual compared to the solar irradiance change on $11 / 07 / 18$. This is true for both cases - when the $\mathrm{PV}$ module is in the open-circuit mode $(x=0)$ and when it is in the full-load mode $(x=1)$. In general, the PV module temperature calculated using the SNL model changes in a similar way as the one calculated using the proposed thermal model for this day. Such a gradual change in the simulated PV module temperature occurs due to small fluctuations of solar irradiation. 


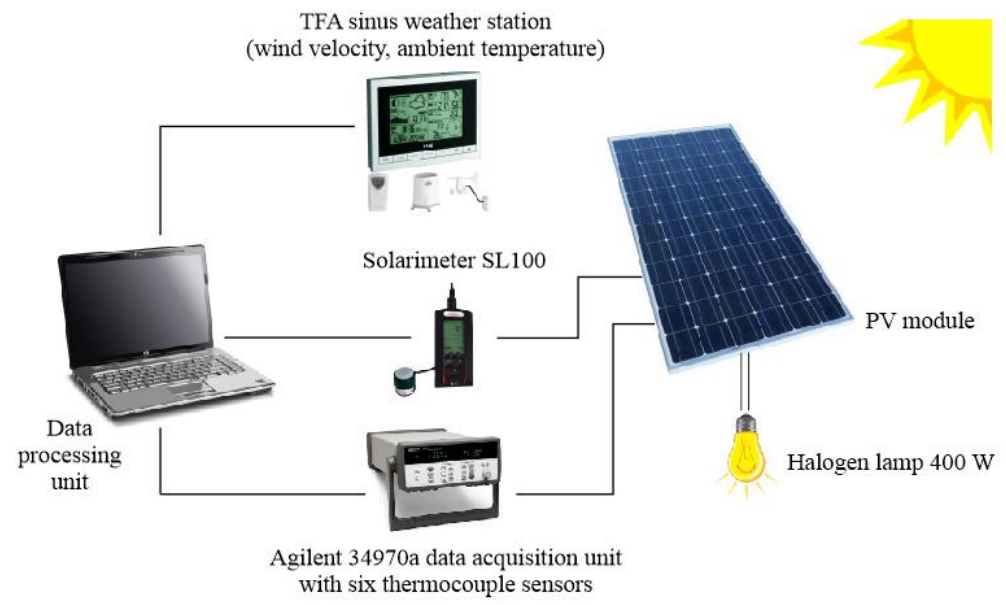

Fig. 3. Simplified schematic of the experimental measurement equipment used in the present study.

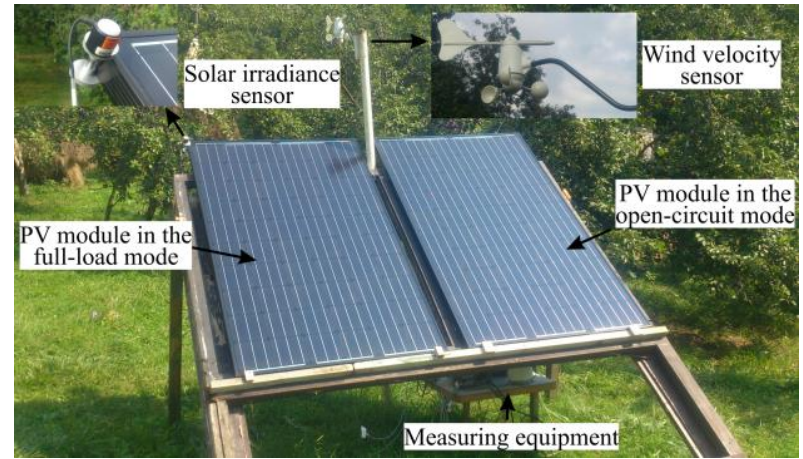

(a)

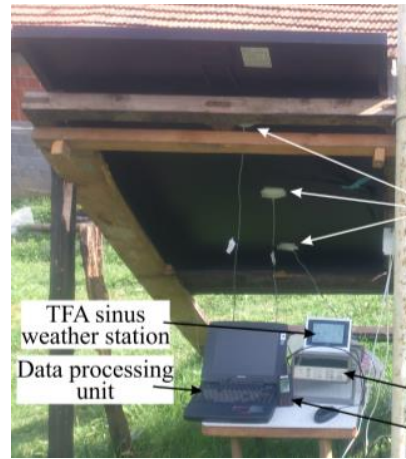

(b)

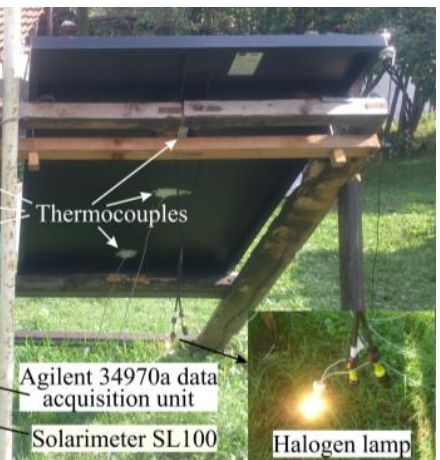

Solarimeter SL100 Halogen lamp

Fig. 4. Photograph of the PV system used: a) Front PV surface; b) back PV surface.

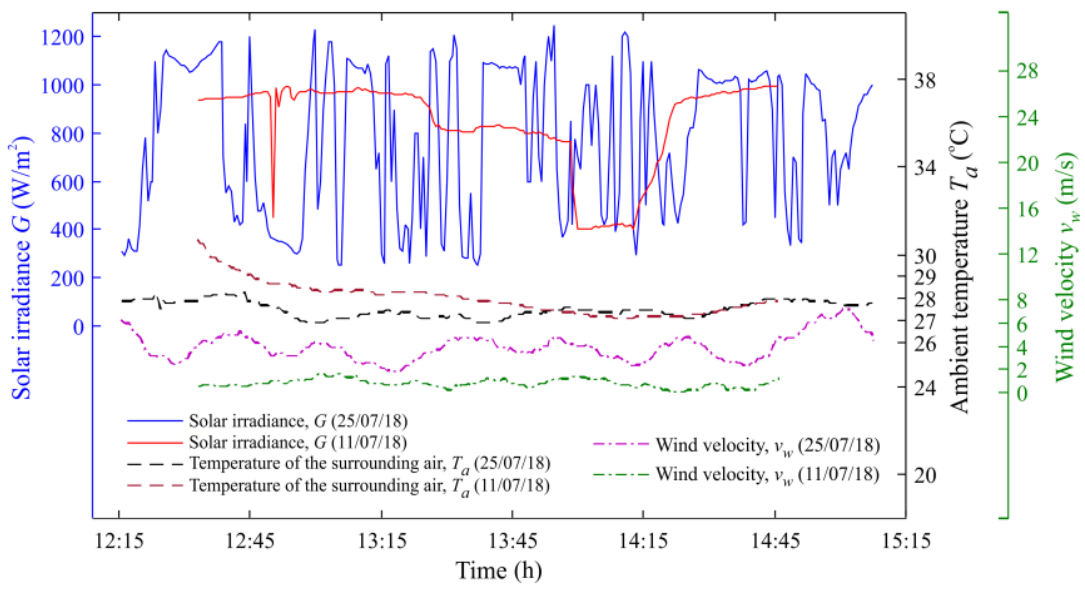

Fig. 5. Data on solar irradiance, ambient temperature and wind velocity during the two considered days (11/07/18 and 25/07/18).

For the second day of measurement (Fig. 7) the proposed thermal model provided two temperature curves very similar to that measured for the two PV modules operating in two considered modes (open-circuit and full-load). During this day, solar irradiance was characterised by rapid fluctuations due to fast moving clouds. Consequently, the measured temperatures for both PV modules changed rapidly. The temperature calculated using the proposed thermal model closely follows the measured temperature curve for the corresponding operating mode with a difference of generally less than $2.5 \mathrm{~K}$. The same does not apply to the PV module temperature calculated using the SNL model. This temperature deviates significantly from the measured one and is in direct proportion to the fluctuations of the solar irradiance curve. This is due to the fact that the SNL model, like all other steady-state models, neglects the thermal capacities of the PV module materials, i.e. it does not include the factor which characterises the thermal lag of a PV module.

The calculated standard errors of the proposed thermal model and the SNL model for the two considered days and two operating modes are given in Table III.

TABLE III. STANDARD ERRORS OF ESTIMATES MADE BY MEANS OF THE PROPOSED AND SNL TEMPERATURE MODELS

\begin{tabular}{|c|c|c|c|}
\hline \multirow{2}{*}{$\begin{array}{c}\text { Day of } \\
\text { measurement }\end{array}$} & \multirow{2}{*}{$\begin{array}{l}\text { Operating } \\
\text { mode }\end{array}$} & \multicolumn{2}{|c|}{$\begin{array}{c}\text { Standard error of predicted } T_{P V} \\
\left({ }^{\circ} \mathrm{C}\right)\end{array}$} \\
\hline & & Proposed model & SNL model \\
\hline \multirow{2}{*}{$11 / 07 / 18$} & Open-circuit & 1.19 & 12.85 \\
\hline & Full-load & 1.02 & 4.91 \\
\hline \multirow{2}{*}{$25 / 07 / 18$} & Open-circuit & 2.00 & 8.62 \\
\hline & Full-load & 1.55 & 10.96 \\
\hline
\end{tabular}




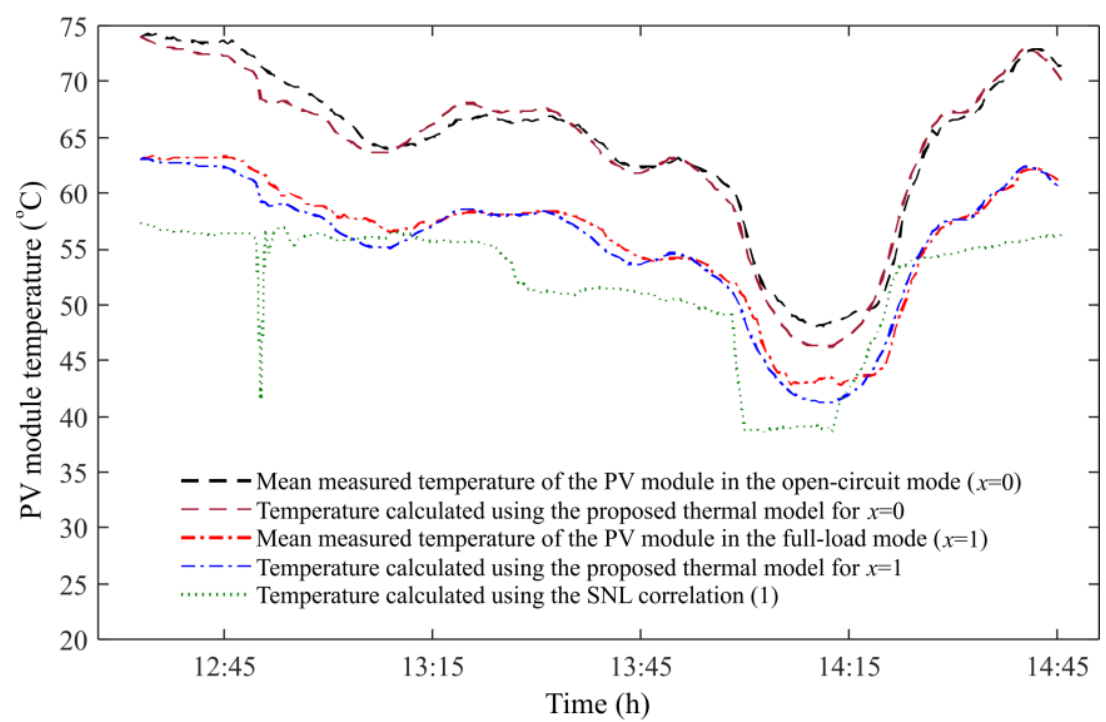

Fig. 6. Measured and simulated PV module temperature for 11/07/18.

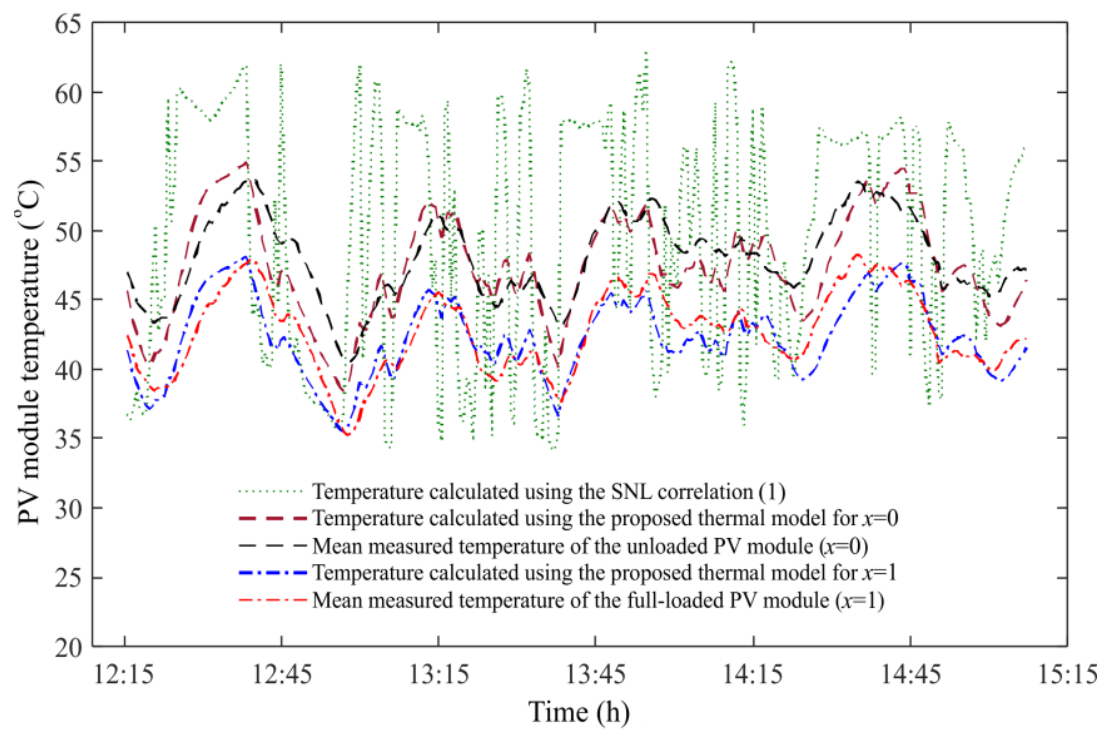

Fig. 7. Measured and simulated PV module temperature for 25/07/18.

The accuracy of the proposed thermal model is best for less changing ambient conditions. More than $90 \%$ of values modelled by the proposed thermal model will fall within the standard error of measurement.

From the Figs. 6 and 7 it is evident that the temperature of the PV module operating in the open-circuit mode is by about $5{ }^{\circ} \mathrm{C}$ higher than the temperature of the PV module operating in the full-load mode under the same ambient conditions. This difference increases with a decrease in the wind velocity. For the considered type of PV modules and under STC conditions, this difference in temperature results in a difference in the estimated power of the PV module of almost $5 \mathrm{~W}$ (this difference in the estimated power was calculated using (19)). This means that in the power system with the solar power plants, it should be ensured that the PV modules always deliver the maximum power, because this saves other non-renewable energy sources and because the repayment period of the solar power plant is shorter.

\section{Conclusions}

During the exploitation of the PV modules a fast change in ambient conditions may occur. In such transient conditions, the PV module temperature predicted by the steady-state models may not follow the real temperature closely, so transient models should be used. A transient thermal model has been developed in order to predict the temperature response time of a PV module operating under varying atmospheric conditions, such as solar irradiation, wind velocity, and ambient temperature. In addition, the model incorporates operating modes and performance characteristics of the PV modules. The model has been experimentally validated by the measurements of the PV module temperature under varying atmospheric conditions. The results shown in Table III and in Figs. 6 and 7 demonstrate that the accuracy of the proposed thermal model is more than adequate for most PV applications. The modelled temperature closely follows the trend of the measured one. The model accuracy is $3{ }^{\circ} \mathrm{C}$ of the measured temperature values $100 \%$ of the time under all conditions. The thermal lag of the module temperature caused by its thermal mass is properly tracked by the proposed model in all cases. The model responds to the transient changes in 
solar irradiance with the same trend as the measured data, slightly increasing the error in the predicted value compared to the cases when the solar irradiance fluctuations are small. Using the proposed thermal model, it is possible to analyse the performance of the PV modules for all operating modes - from the open-circuit mode (when it is $x=0$ ) to its full-load mode (when it is $x=1$ ). It is found that the PV module temperature in the open-circuit mode is by about $5{ }^{\circ} \mathrm{C}$ higher than the corresponding PV module temperature in the fullload mode under the same ambient conditions. This difference is dependent on the intensity of the solar radiation and wind velocity, and certainly cannot be ignored in the case when the precise analysis of the PV module performance is required.

The transient thermal model presented in this paper differs from the model of Fuentes [7] in that it is simpler (does not require knowledge of INOCT), as well as from the models presented by Jones and Underwood [8], and Luketa-Hanlin and Stein [10] in the following aspects:

1. The forced convection coefficients are calculated using the power-low correlations which are more appropriate than the linear ones;

2. The PV module temperature is obtained iteratively, which increases the accuracy of the model.

The influence of the load level relative to the nominal power of the PV module on its temperature is considered in the proposed model. This is carried out for the first time in a model of this kind.

The proposed thermal model, among other things, may be used in software such as HOMER for the design and optimisation of micro-grid and distributed generation power systems containing PV modules.

\section{REFERENCES}

[1] E. Skoplaki, J. A. Palyvos, "On the temperature dependence of photovoltaic module electrical performance: A review of efficiency/power correlations", Solar Energy, vol. 83, no. 5, pp. 614624, 2009. DOI: 10.1016/j.solener.2008.10.008.

[2] E. Skoplaki, A. G. Boudouvis, J. A. Palyvos, "A simple correlation for the operating temperature of photovoltaic modules of arbitrary mounting", Solar Energy Materials and Solar Cells, vol. 92, no. 11, pp. 1393-1402, 2008. DOI: 10.1016/j.solmat.2008.05.016.

[3] M. Mattei, G. Notton, G. Cristofari, M. Muselli, P. Poggi,
"Calculation of the polycrystalline PV module temperature using a simple method of energy balance", Renewable Energy, vol. 31, no. 4, pp. 553-567, 2006. DOI: 10.1016/j.renene.2005.03.010.

[4] E. Kaplani, S. Kaplanis, "Thermal modelling and experimental assessment of the dependence of PV module temperature on wind velocity and direction, module orientation and inclination", Solar Energy, vol. 107, pp. 443-460, 2014. DOI: 10.1016/j.solmat.2008.05.016.

[5] A. Q. Jakhrani, A. K.. Othman, A. R. H. Rigit, S. R. Samo, "Comparison of solar photovoltaic module temperature models", World Applied Science Journal, vol. 14, pp. 1-8, 2011.

[6] E. Skoplaki, J. A. Palyvos, "Operating temperature dependence of photovoltaic module: A survey of pertinent correlations", Renewable Energy, vol. 34, no. 1, pp. 23-29, 2009. DOI: 10.1016/j.renene.2008.04.009.

[7] M. K. Fuentes, "A simplified thermal model for flat-plate photovoltaic arrays", Sandia National Laboratories, Albuquerque, NM, Sandia Report SAND-85-0330, 1987.

[8] A. D. Jones, C. P. Underwood, "A thermal model for photovoltaic systems", Solar Energy, vol. 70, no. 4, pp. 349-359, 2001. DOI: 10.1016/S0038-092X(00)00149-3.

[9] M. De Rosa, G. Romano, C. Rossi, F. Scarpa, L. A. Tagliafico, "Dynamic thermal model for hybrid photovoltaic panels", Energy Procedia, vol. 81, pp. 345-353, 2015. DOI: 10.1016/j.egypro.2015.12.104.

[10] A. Luketa-Hanlin, J. Stein, "Improvement and Validation of a Transient Model to Predict Photovoltaic Model Temperature", Sandia National Laboratories, Albuquerque, NM, Sandia Report SAND2012 4307, 2012.

[11] D. L. King, W. E. Boyson, J. A. Kratochvil, "Photovoltaic array performance model", Sandia National Laboratories, Albuquerque, NM, Sandia Report SAND2004-3535, 2004.

[12] T. Fujii, H. Imura, "Natural-convection heat transfer from a plate with arbitrary inclination", International Journal of Heat and Mass Transfer, vol. 15, no. 4, pp. 755-764, 1972. DOI: 10.1016/00179310(72)90118-4.

[13] D. A. Adkins, "Wind convection coefficient correlations for CPV modules", in Conf. Rec. 2013 IEEE Photovoltaic Specialists Conference (PVSC), 2013, pp. 3421-3425. DOI: 10.1109/PVSC.2013.6745183.

[14] R. S. Balog, Y. Kuai, G. Uhrhan, "A photovoltaic module thermal model using observed insolation and meteorological data to support a long life, highly reliable module-integrated inverter design by predicting expected operating temperature", in Conf. Rec. 2009 IEEE Energy Conversion Congress and Exposition (ECCE), 2009, pp. 3343-3349. DOI: 10.1109/ECCE.2009.5316107.

[15] W. C. Swinbank, "Long wave radiation from clear skies", Quarterly Journal of the Royal Meteorological Society, vol. 89, no. 381, pp. 339-348, 1963. DOI: 10.1002/qj.49708938105.

[16] S. Armstrong, W. G. Hurley, "A thermal model for photovoltaic panels under varying atmospheric conditions", Applied Thermal Engineering, vol. 30 , no. $11-12$, pp. 1488-1495, 2010. DOI: 10.1016/j.applthermaleng.2010.03.012. 